\title{
Low velocity failure and integrity assessment of foam core sandwich panels
}

\author{
Oana Alexandra Mocian, Dan Mihai Constantinescu, Ştefan Sorohan, Marin Sandu \\ University POLITEHNICA of Bucharest, Department of Strength of Materials, 060042 Bucharest, Romania \\ mocianoana@gmail.com, https://orcid.org/0000-0003-3093-7788 \\ dan.constantinescu@upb.ro, https://orcid.org/0000-0001-5400-7804 \\ stefan.soroban@upb.ro,bttps://orcid.org/0000-0002-9400-5843 \\ marin.sandu@upb.ro, bttps://orcid.org/0000-0002-9183-5104
}

ABSTRACT. Impact resistance and energy absorbing capability are of great interest in the design of composite sandwich structures. This paper experimentally studies damage, failure and energy absorption properties of foam core sandwich panels with aluminum and glass fiber reinforced plastic (GFRP) facesheets subjected to low velocity impact. Tests are performed using a drop weight impact tower at different impact velocities. The energy absorbing capabilities of aluminum and composite facesheet sandwich panels with PUR and PS foam core are evaluated by means of absorbed energy-time histories and by specific parameters as normalized absorbed energy, specific energy absorption, and crush force efficiency. Stiffer panels behave better at lower impact velocities, while more ductile ones do better if impact energy is increased.

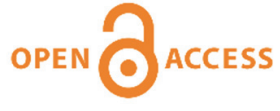

Citation: Mocian, O.A., Constantinescu, D.M., Sorohan, St., Sandu, M., Low velocity failure and integrity assessment of foam core sandwich panels, Frattura ed Integrità Strutturale, 48 (2019) 230-241.

Received: 20.01.2019

Accepted: 15.02.2019

Published: 01.04.2019

Copyright: (C) 2019 This is an open access article under the terms of the CC-BY 4.0, which permits unrestricted use, distribution, and reproduction in any medium, provided the original author and source are credited.

KEYWORDS. Low velocity impact; Sandwich panels; Skin and core damage; Energy absorption parameters.

\section{INTRODUCTION}

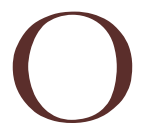
ne of the main design drivers of modern engineering is weight reduction whilst still ensuring high level of operational safety. Lightweight design can protect human life, avoid financial losses and reduce vehicles emissions. Seeking suitable lightweight materials has led to the development of composite materials, plastics and alternative new materials and sandwich construction. The last, usually consists of two strong and stiff facesheets separated by a lowdensity core. Faces are generally made of metal alloys [1], fiber reinforced composites [2] or fiber metal laminates [3] and are responsible for carrying the transverse loads or bending moments. The core of sandwich structures comprises of honeycombs [4], corrugated materials [5], polymeric/metallic foams [6, 7], lattices [8] or balsa wood [9] and is responsible for absorbing the impact energy by local plastic deformation whilst still offering enough overall support to prevent high local bending strains in the facesheets. A comprehensive review of the current trends in the research and applications of sandwich structures is done by Birman and Kardomateas, [10]. During service life, sandwich structures may be subjected to 
several severe impacts arising from operational events like collision, flying debris, tool drop or bird strike. Among these, low velocity impacts can severely reduce the strength of the whole structure due to indentation and localized internal skin and/or core damage [11, 12], without any perception on the impacted side, [13-15]. As mentioned by Feng and Aymerich [15] the low velocity impact can develop various damage patterns in sandwich composites as resulting from different failure mechanisms as: matrix cracking, fiber fracture, face-core debonding through delaminations, and core crushing. All of them interact through complicated synergies when increasing the impact energy.

Many research results can be found in the aspects of quasi static, dynamic and energy absorption characteristics. In the studies of Steeves et al. [16], Jiang et al. [17] and Vitale et al. [18], the collapse of a sandwich beam under three-point bending was analyzed through several types of failure events: core shear, face micro buckling, facesheet indentation and core crushing, depending on the geometry and density of the foam core. The dominant regimes of each collapse mode were marked out by drawing failure maps. The predictions were found close to the experimental results. Sokolinsky et al. [19] used linear higher-order sandwich panel theory (HSAPT) to describe the mechanical response of sandwich beams with aluminum facesheets and PVC foam core. They showed that the linear HSAPT can be efficiently used to estimate vertical displacements of soft-core sandwich beams up to high load levels with great accuracy. Zhang et al. [20] studied the flexural performance of composite sandwich beams with different GFRP ribs in four-point bending tests and concluded that beams failed due to skin compressive failure when positioned edgewise and in core shear failure when positioned flatwise. Styles et al. [21] investigated the effect of core thickness on the failure behavior of aluminum foam core sandwich structures under flexural loading using the 3D digital image correlation method. A full field strain analysis for each core thickness was conducted and different failure mechanisms were found.

Regarding the dynamic impact investigations of sandwich structures, attention has gradually shifted from experimental testing to analytical analysis and numerical simulation due to the high cost of testing and the inability to accurately capture the damage states, especially in the case of low velocity impact where damage is nearly imperceptible. Extensive studies have been recently made on sandwich structures with composites as facesheets. In [22] analytic and semi-analytic solutions have been obtained for the quasi-static case in studying the problem of damage progression and interaction in a sandwich beam with laminated facesheets and a homogeneous core. It was shown that core/facesheet interactions generate energy barriers to the propagation of delaminations in the facesheet; this explains the experimental findings of low velocity impact tests showing that in some cases multiple delamination damage in the facesheet typically remains localized near the striker. A procedure to numerically simulate the low-velocity impact tests and residual flexural strength tests of sandwich structures was developed by the VUMAT subroutine in ABAQUS/Explicit, [23]. The damage morphology of both facesheets and the corrugated core was clearly identified. The numerical and experimental load-displacement characteristics for all cases were compared and there was a reasonably good agreement between them, except for the prolonged load plateau stage when the predicted load overestimated the experimental result, probably because the interface debonding was not considered in the numerical simulation. Funari et al. [24] developed a much more refined numerical technique by incorporating in the model moving mesh cohesive modelling, crack initiation and nucleation at core/skin interfaces. Arbitrary Lagrangian-Eulerian (ALE) interface elements were used for the sandwich structure combined with a cohesive fracture approach where debonding phenomena may occur in presence of multiple delaminations. It is therefore realized a reduction of the computational costs, required to predict crack onset and progressive evolution of debonding phenomena. Cohesive models for sandwich core/skin interfaces were calibrated by means of comparisons with numerical and experimental data for mode I and mode II configurations. They also studied, [25], the influence of inertial effects on debonding phenomena and crack propagation in different core typologies of sandwich structures based on fracture parameters determined experimentally on commercially available foams.

Park et al. [26] investigated the force-time history curves of impacted sandwich structures and concluded that the damage resistance appears to be dependent on both the facesheet materials and core thickness: the lower the stiffness becomes, the greater the core thickness affects the impact resistance. Crupi et al. [27] conducted a theoretical and experimental analysis for the impact response of glass fiber reinforced aluminum honeycomb sandwiches. They used 3D computed tomography to investigate the failure mode and internal damage and demonstrated that the use of glass-epoxy reinforcement on aluminum honeycomb sandwiches enhanced the energy absorption and load carrying capacities. Zhu et al. [28] studied through theoretical, experimental and numerical methods the damage and failure mode maps of composite sandwich panels subjected to quasi-static indentation and low velocity impact. The effect of facesheet thickness was found to be vital contribution to the failure mode and its corresponding ultimate load, while core density affected only the failure mode. Dawood et al. [29] demonstrated through experimental and numerical means that the punching resistance of GFRP sandwich panels with balsa wood cores can be increased by locally stiffening the panels near the location of the concentrated load. The low velocity impact response in metallic facesheets such as titanium, stainless steel and aluminum is different from composites as metals are ductile under localized deformation. Xie et al. [30] studied the low velocity impact response of 
titanium honeycomb sandwich structures through experimental and numerical investigations. The identified failure modes were permanent indentation on the impacted facesheet and localized honeycomb core crush under the impact location. Sun et al. [31] studied the effect of skin thickness, core thickness, core height and cell size on indentation characteristics, such as peak forces, failure modes and energy absorption, for sandwich panels with aluminum facesheets and honeycomb core. The principal failure mechanisms identified were shear and tension damage for the facesheets and plastic folding and buckling for the honeycomb core. The parametric studies conducted through numerical analysis revealed that by modifying the cell size changed considerably the failure modes and by increasing the core height decreased the peak forces.

Despite the extensive research conducted in low velocity impact of sandwich structures, a considerable amount of research is still needed to reveal their complex damage and failure characteristics. In this study, the damage and failure mechanism and energy absorption properties of foam core sandwich panels with aluminum and GFRP facesheets subjected to low velocity impact are investigated. Drop weight impact tests are carried out to induce damage into the sandwich panels. Different impact velocities are selected as to cause different damage response of the sandwich panels, from barely visible impact damage to complete perforation. Damage characteristics are evaluated by measuring the damaged area or depth of indentation of the impactor and energy absorption is evaluated by using specific parameters as: normalized absorbed energy, specific energy absorption and crush force efficiency.

\section{EXPERIMENTAL METHODOLOGY}

\section{Materials and specimens}

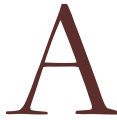
Il tested sandwich panels consist of two identical facesheets and a foam core. Facesheets are of two major types: aluminum and composite. The aluminum is $\mathrm{Al} \mathrm{6082-T6,} \mathrm{which} \mathrm{is} \mathrm{one} \mathrm{of} \mathrm{the} \mathrm{strongest} \mathrm{alloys} \mathrm{from} \mathrm{the} \mathrm{6xxx} \mathrm{series,}$ due to the heat-treated and artificially aged processes. The thickness of the aluminum facesheets is $1.5 \mathrm{~mm}$. The composites are made from 8 layers of fiber glass roving of $500 \mathrm{~g} / \mathrm{m}^{2}$ and a general-purpose epoxy system, EPOLAM 2017. Three different types of composite facesheets were obtained by adding different amounts of short glass fibers in the resin matrix: type A - $0 \mathrm{~g}$ of short glass fibers / $100 \mathrm{~g}$ resin, type B - $6.4 \mathrm{~g}$ of short glass fibers / $100 \mathrm{~g}$ resin and type C - $9.3 \mathrm{~g}$ of short glass fibers / $100 \mathrm{~g}$ resin. Thickness of the facesheets slightly varies around $2 \mathrm{~mm}$ due to the manual manufacturing process. The foams used as core for the sandwich panels are polyurethane (PUR) Necuron 100 of density $100 \mathrm{~kg} / \mathrm{m}^{3}$ and commercial extruded polystyrene (PS) of density $32 \mathrm{~kg} / \mathrm{m}^{3}$, both having thicknesses of $12 \mathrm{~mm}$. Facesheets were bonded to the core using an epoxy adhesive, type Araldite AW106 (Huntsman). The panels were cut into square specimens of 140x140 $\mathrm{mm}$.

\section{Low velocity impact testing}

Impact tests were conducted according to ISO 6603-2:2000 [32] and ASTM 7136 [33] standards, using an instrumented impact tower presented in Fig. 1. The INSTRON Ceast 9340 is a gravitationally accelerated impact drop tower that can reach impact velocities up to $4.6 \mathrm{~m} / \mathrm{s}$ and impact energies of almost $430 \mathrm{~J}$. It is equipped with an instrumented impactor, having a hemispherical head of $20 \mathrm{~mm}$ diameter, which can directly measure the impact force using a strain gauge transducer which is mounted inside, on an elastic element. The sandwich plates are placed on an adjustable in height test specimen support with a circular hole of $100 \mathrm{~mm}$ diameter (Fig. 1), which eventually allows the striker to fall if the plate is perforated. A clamping ring is pressed over the sandwich plate by a pneumatic system with a maximum force of $3 \mathrm{kN}$. This force cannot be adjusted during testing. The machine's software allows the user to obtain other impact characteristics such as: absorbed energy, displacement of the impactor, and of course the measured contact force during impact. Therefore force-time and force-displacement plots can be easily obtained.

Data acquisition was done with a frequency of $200 \mathrm{kHz}$ for a maximum estimated time of $40 \mathrm{~ms}$ which proved as being sufficient to follow all the significant events. Only the first impact was considered for monitoring the impact phenomena and comparisons of the responses of the sandwich panels which were tested. Details of the experimental procedure can be found in previous work $[34,35]$.

The objective of the impact tests was to cause impact damage to the panels, from barely visible impact damage to complete perforation. Several specimens were tested at impact velocities ranging between 1.5 and $4.5 \mathrm{~m} / \mathrm{s}$ in order to select the impact velocities that manage to cause various failure mechanisms. Three impact velocities were selected hereby: $3 \mathrm{~m} / \mathrm{s}, 3.5 \mathrm{~m} / \mathrm{s}$ and $4 \mathrm{~m} / \mathrm{s}$ and a constant mass of the impactor as $13.15 \mathrm{~kg}$. The corresponding impact energies and drop heights are presented in Tab. 1.

The impacted sandwich panels were abbreviated as following: sandwich panel (SP) with composite type (A, B or C) or aluminum (Al) facesheets, foam core type (PUR or PS) and impact velocity. Therefore, as an example, SPA_PUR_3 means 
sandwich panel with composite facesheets type A and polyurethane foam core impacted at $3 \mathrm{~m} / \mathrm{s}$.

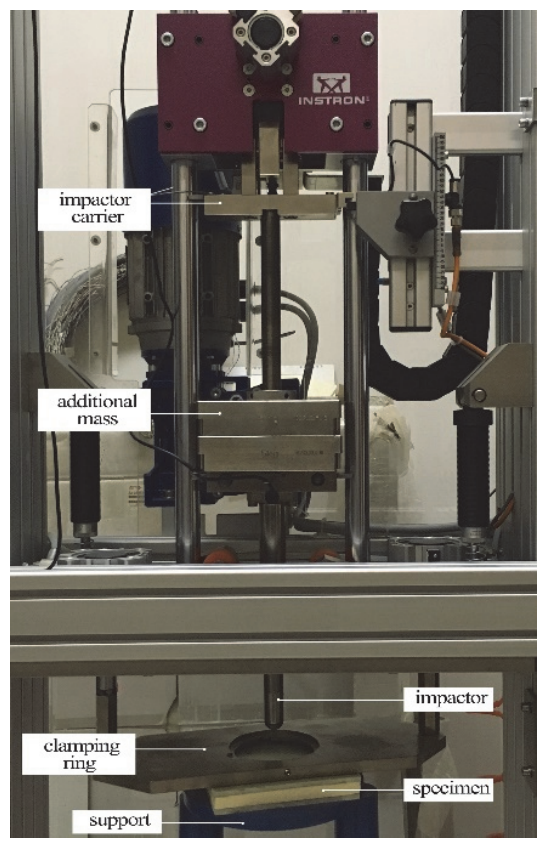

Figure 1: INSTRON Ceast 9340 drop tower impact system.

\begin{tabular}{ccc}
\hline $\begin{array}{c}\text { Impact velocity } \\
{[\mathrm{m} / \mathrm{s}]}\end{array}$ & $\begin{array}{c}\text { Impact energy } \\
{[]}\end{array}$ & $\begin{array}{c}\text { Drop height } \\
{[\mathrm{mm}]}\end{array}$ \\
3 & 59.17 & 460 \\
3.5 & 80.54 & 625 \\
4 & 105.2 & 815 \\
\hline
\end{tabular}

Table 1: Impact characteristics of the drop weight tests: impact velocity, impact energy and drop height.

\section{RESULTS AND DISCUSSIONS}

uring an impact test, the variation of the impact force in time is recorded by the drop tower impact system. Using these data, the software calculates other variations such as impact energy in time and impact force as a function of impactor displacement. It also determines some impact parameters such as peak force, corresponding to the maximum value on the force-time curve, and absorbed energy, calculated as the area under the force-displacement curve. The average values of mass, maximum impact force and absorbed energy of the impacted sandwich panels are listed in Tab. 2.

\begin{tabular}{|c|c|c|c|c|c|c|c|c|c|c|c|c|c|}
\hline \multirow{2}{*}{$\begin{array}{l}\text { Sandwich } \\
\text { panel }\end{array}$} & \multicolumn{2}{|c|}{ Mass [g] } & \multicolumn{2}{|c|}{$\mathrm{F}_{\max }[\mathrm{N}]$} & \multicolumn{2}{|c|}{$\mathrm{E}_{\text {abs }}[\mathrm{J}$} & \multirow{2}{*}{$\begin{array}{l}\text { Sandwich } \\
\text { panel }\end{array}$} & \multicolumn{2}{|c|}{ Mass [g] } & \multicolumn{2}{|c|}{$\mathrm{F}_{\max }[\mathrm{N}]$} & \multicolumn{2}{|c|}{$\mathrm{E}_{\text {abs }}[\mathrm{J]}$} \\
\hline & PUR & PS & PUR & PS & PUR & PS & & PUR & PS & PUR & PS & PUR & PS \\
\hline SPA_3 & 162 & 137 & 5563 & 4336 & 57.97 & 57.88 & SPC_3 & 172 & 173 & 5804 & 4847 & 59.47 & 58.25 \\
\hline SPA_3.5 & 163 & 138 & 5705 & 4442 & 76.02 & 66.54 & SPC_3.5 & 163 & 165 & 5463 & 5185 & 76.63 & 83.03 \\
\hline SPA_4 & 161 & 144 & 6151 & 4825 & 84.82 & 80.30 & SPC_4 & 172 & 174 & 5839 & 6015 & 86.26 & 92.66 \\
\hline SPB_3 & 175 & 168 & 5850 & 4669 & 57.78 & 57.18 & SPAl_3 & 198 & 184 & 10981 & 6985 & 50.84 & 58.03 \\
\hline SPB_3.5 & 165 & 160 & 5555 & 5025 & 81.11 & 78.35 & SPAl_3.5 & 199 & 185 & 11789 & 8261 & 78.45 & 76.62 \\
\hline SPB_4 & 170 & 164 & 6045 & 4935 & 85.00 & 78.14 & SPAl_4 & 193 & 184 & 11061 & 10030 & 99.20 & 100.30 \\
\hline
\end{tabular}

Table 2: Parameters of impacted sandwich panels. 


\section{Energy absorption}

Fig. 2 presents typical energy variation curves as a function of time for all tested sandwich panels. Results are presented comparatively in terms of core type and impact velocity, for each type of facesheet.

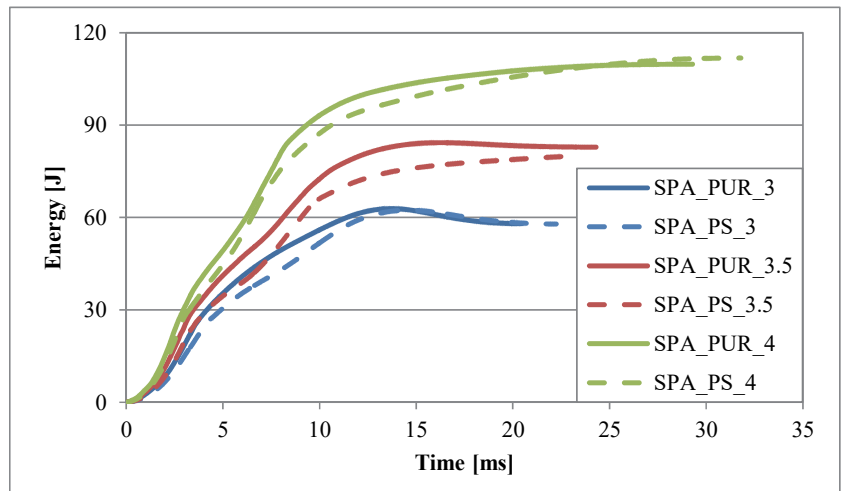

a)

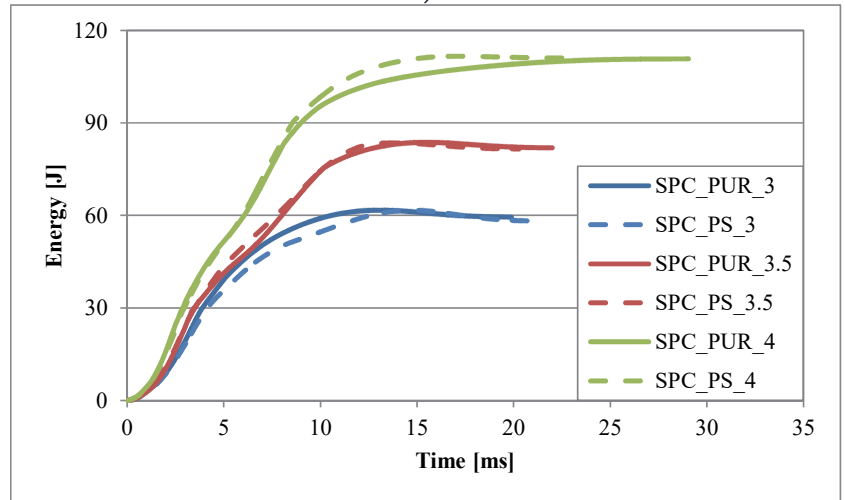

c)

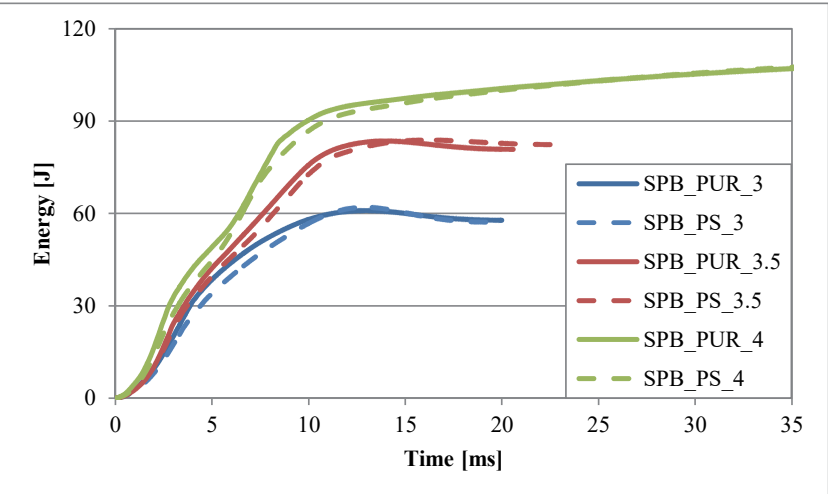

b)

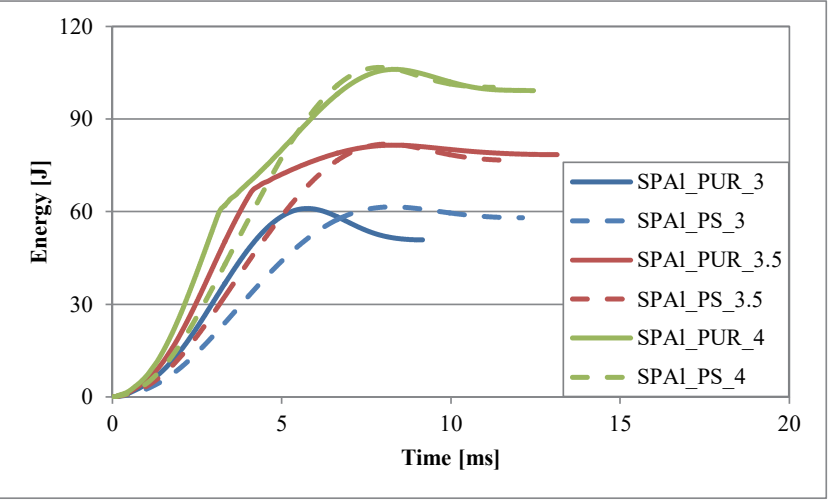

d)

Figure 2: Variation of energy in time for different facesheet types: a) composite type A; b) composite type B; c) composite type C; d) aluminum.

Three important particularities can be identified in the energy-time variation curve: the impact energy corresponding to the maximum value on the curve, the absorbed energy corresponding to the constant value on the curve after the decrease of energy and the elastic recovered energy represented by the difference between the impact and absorbed energy. If the curve shows an increase of the energy in time it results that the panel has been perforated (Figs. 2 a, b, c at 4 m/s and PUR foam core, as an example). In all cases the absorbed energy increases with increasing impact energy. For sandwich panels with aluminum facesheets there is always a recovery of energy regardless the impact velocity. Instead, for sandwich panels with composite facesheets, a recovery of energy is achieved only for the smallest impact velocity of $3 \mathrm{~m} / \mathrm{s}$.

Not only the impact velocity influences the absorbed energy but also the facesheet and core type (see Fig. 3). When using PUR foam as core, for the impact velocity of $3 \mathrm{~m} / \mathrm{s}$, the sandwich panels with aluminum facesheets absorb approximately $13 \%$ less impact energy than those with composite facesheets. On the contrary, sandwich panels with PS core absorb almost the same amount of energy, regardless the facesheet type, due to its elastic behavior. At $3.5 \mathrm{~m} / \mathrm{s}$ all panels with PUR foam core (Fig. 3a) absorb almost the same amount of impact energy. For panels with PS foam core (Fig. 3b), the highest amount of energy is absorbed by those with composite facesheets type C, approximately $25 \%$ more than those with composite facesheets type A, which absorb the smallest amount of energy. For the highest impact velocity, sandwich panels with aluminum facesheets absorb the same amount of energy, regardless the foam core type. Composite sandwich panels absorb considerably less energy, approximately $14 \%$ less, since they are completely perforated at this impact velocity, except the case of sandwich panel with composite facesheets type $\mathrm{C}$ and PS foam core.

The energy absorption can also be quantified by several parameters, such as: normalized absorbed energy (NAE - ratio between absorbed energy and initial impact energy), specific energy absorption (SEA - ratio between absorbed energy and mass) and crush force efficiency (CFE - ratio between average crushing force and peak force), [36]. These parameters are comprised in Tab. 3 and graphically illustrated in Fig. 4. 


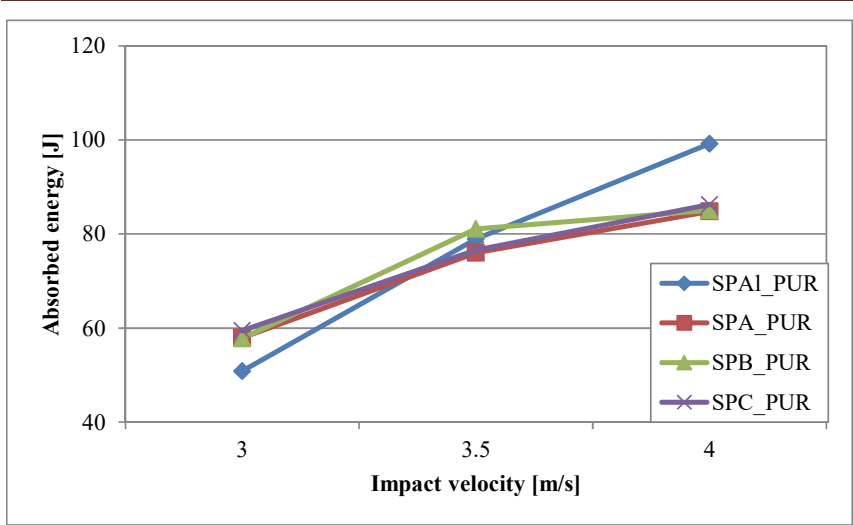

a)

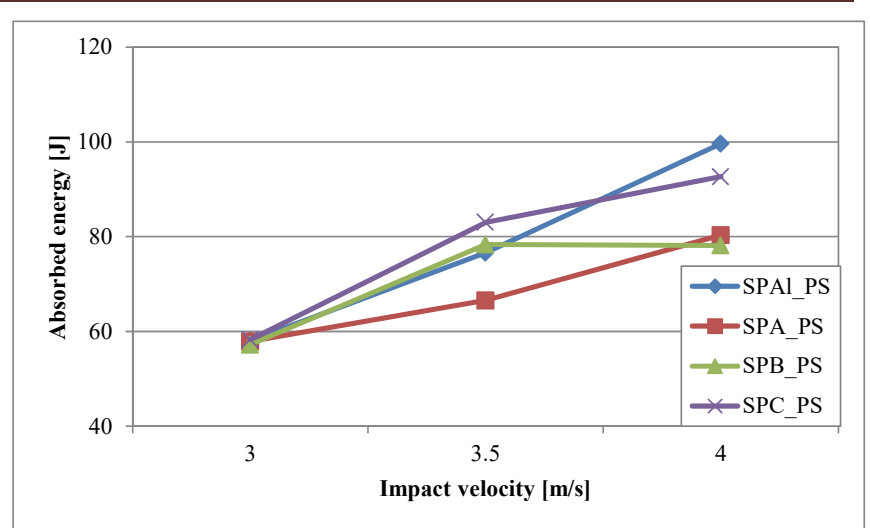

b)

Figure 3: Comparison of absorbed impact energy as a function of facesheet type: a) PUR foam core; b) PS foam core.

\begin{tabular}{lllllllllllllll}
\hline \multirow{2}{*}{$\begin{array}{l}\text { Sandwich } \\
\text { panel }\end{array}$} & \multicolumn{2}{l}{ NAE [\%] } & \multicolumn{3}{l}{ SEA J $/ \mathrm{kg}]$} & \multicolumn{2}{l}{ CFE [-] } & \multicolumn{2}{l}{ Sandwich } & \multicolumn{2}{l}{ NAE [\%] } & \multicolumn{2}{l}{ SEA [J/kg] } & \multicolumn{2}{l}{ CFE [-] } \\
SPA_3 & 97.96 & 97.81 & 357.97 & 423.7 & 0.47 & 0.54 & SPC_3 & 98.78 & 98.45 & 346.68 & 336.82 & 0.43 & 0.50 \\
SPA_3.5 & 94.39 & 82.62 & 465.46 & 483.73 & 0.54 & 0.58 & SPC_3.5 & 95.15 & 99.42 & 468.99 & 504.58 & 0.59 & 0.67 \\
SPA_4 & 80.63 & 76.33 & 526.05 & 556.13 & 0.56 & 0.62 & SPC_4 & 82.00 & 88.07 & 500.52 & 531.55 & 0.59 & 0.60 \\
SPB_3 & 97.65 & 96.63 & 329.40 & 339.73 & 0.43 & 0.58 & SPAl_3 & 85.94 & 98.06 & 257.23 & 315.62 & 0.56 & 0.60 \\
SPB_3.5 & 98.37 & 97.27 & 492.25 & 490.85 & 0.62 & 0.63 & SPAl_3.5 & 97.41 & 95.13 & 393.54 & 414.44 & 0.36 & 0.60 \\
SPB_4 & 80.81 & 74.28 & 499.72 & 473.67 & 0.55 & 0.61 & SPAl_4 & 94.30 & 95.32 & 514.49 & 545.86 & 0.49 & 0.59 \\
\hline
\end{tabular}

Table 3: Energy absorption quantifying parameters.

For sandwich panels with composite facesheets, irrespective of core type, the normalized absorbed energy decreases with increasing impact velocity, respectively with increasing impact energy (see Fig. 4). This happens because the impact energy exceeds the saturation energy, which represents the maximum impact energy that can be absorbed by a structure until it completely loses its load carrying capacity. As it will be further seen in this study, most of the sandwich panels with composite facesheets are perforated at higher impact velocities, meaning that they absorbed only a part of the total impact energy. The rest remained in the impactor as residual velocity. In the case of sandwich panels with aluminum facesheets, at higher impact velocities, NAE slightly increases for panels with PUR foam core and decreases for panels with PS foam core. Due to its elastic behavior the PS foam core manages to better absorb the impact energy at lower impact velocities than the PUR core. The higher values of SEA for sandwich panels with composite facesheets indicate that these panels absorb more energy per unit mass than those with aluminum facesheets. This is because the average weight of sandwich panels with composite facesheets is approximately $15 \%$ less than of those with aluminum facesheets. Also, sandwich panels with composite facesheets absorb a greater amount of energy than those with aluminum facesheets, especially for the lowest impact velocity, due to the different and complex energy absorption mechanisms: matrix cracking, debonding, fiber rupture, core crushing and delaminations.

This type of failure determines a small value for the CFE parameter. For a structure to have good energy absorption capabilities, both SEA and CFE parameters should have high values. From Fig. 4 b) and c) although aluminum sandwich panels with both PUR and PS foam core have the highest values for CFE at $3 \mathrm{~m} / \mathrm{s}$, they have the smallest value for SEA. Consequently, even though they fail in a progressive mode they do not manage to absorb enough impact energy per unit mass. At this impact velocity, the sandwich panel with composite facesheets type A and PS foam core proves to be the most efficient, with SEA of almost $425 \mathrm{~J} / \mathrm{kg}$ and CFE as 0.54 . Though, as it will be later seen in this study, this panel is also the most damaged one at $3 \mathrm{~m} / \mathrm{s}$. The CFE parameter for aluminum sandwich panels with PUR foam core considerably reduces its value at higher impact velocities. For example, at $3.5 \mathrm{~m} / \mathrm{s}$ reaches a value of 0.36 , which is $35 \%$ less than for the lowest impact velocity of $3 \mathrm{~m} / \mathrm{s}$. Instead, the value of the CFE parameter for sandwich panels with aluminum facesheets and PS foam core remains almost the same, around 0.60 , irrespective of impact velocity. For impact velocities of $3.5 \mathrm{~m} / \mathrm{s}$ and 4 
$\mathrm{m} / \mathrm{s}$, composite sandwich panels have higher values for both SEA and CFE than those with aluminum facesheet. Though, at $4 \mathrm{~m} / \mathrm{s}$ they completely lose their load bearing capacity, being completely perforated.

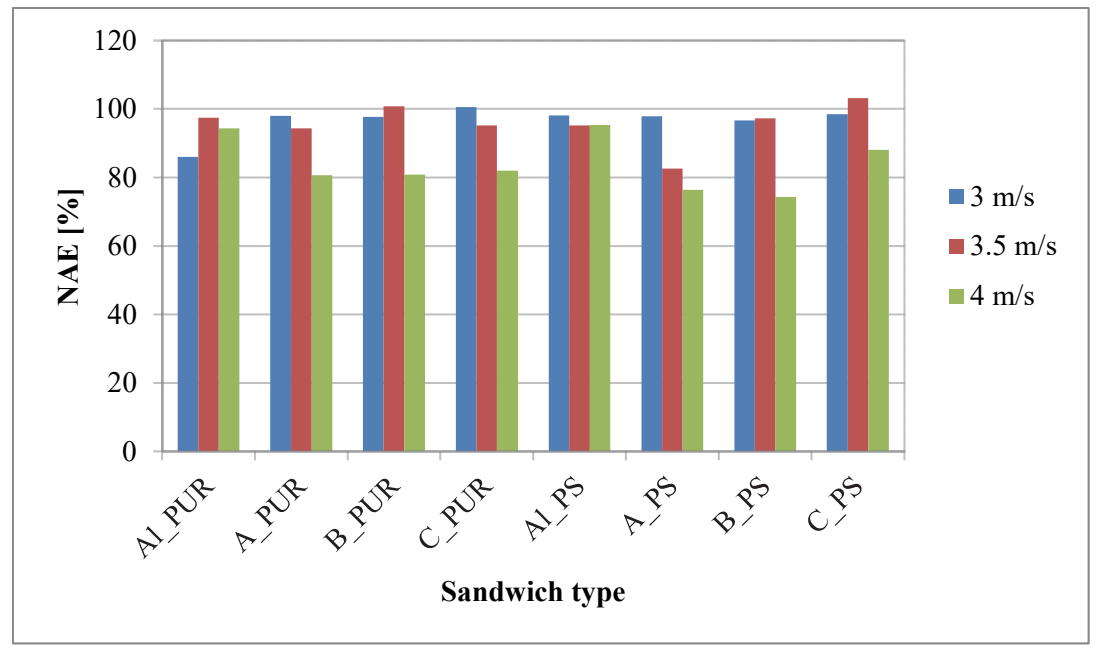

a)

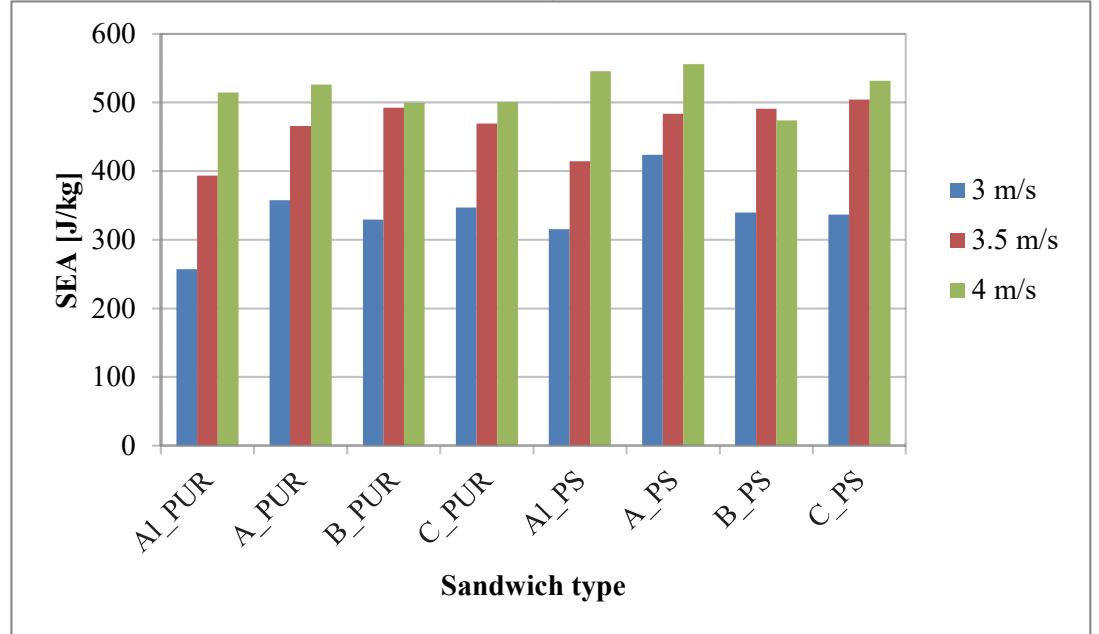

b)

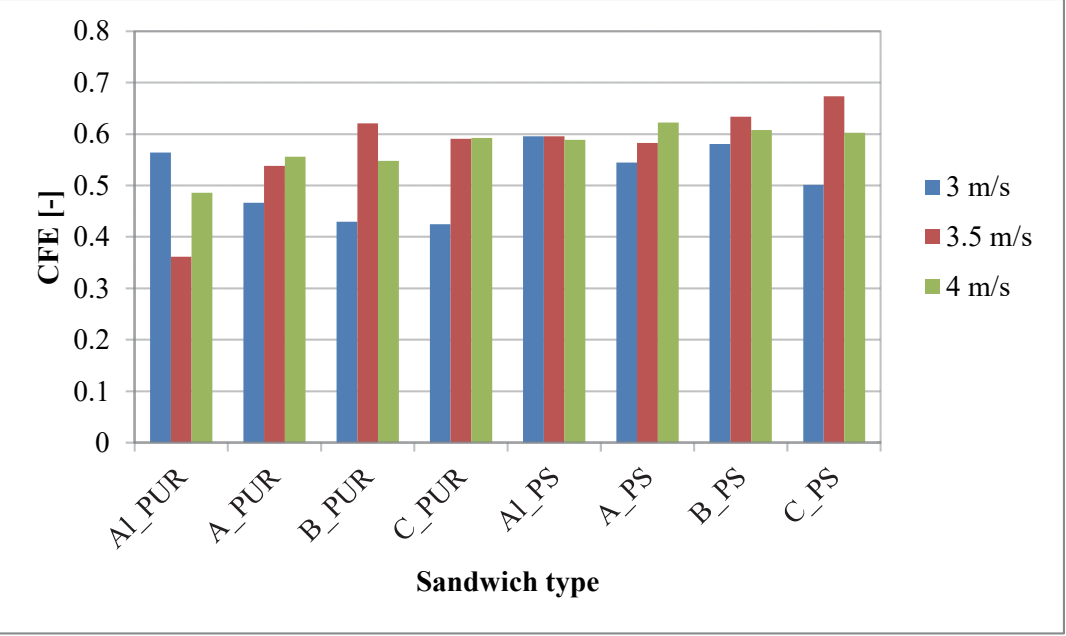

c)

Figure 4: Comparison of energy absorption quatifying parameters as a function of impact velocity: a) NAE; b) SEA; c) CFE. 
Damage assessment

Impact damage assessment of the tested sandwich panels was carried out through visual inspection on the front and back facesheets of the panels. High resolution photographs were taken to assesS the damage extension for all adopted impact velocities. This images were used to measure the damaged areas in sandwich panels with composite facesheets using the ImageJ software [37], which is an open source image processing program designed for scientific multi-dimensional images. For panels with aluminum facesheets the indentation depth, defined as the residual depth of the depresion of the aluminum facesheet surface caused by the impactor during the impact event, was measured. Results are presented in Tab. 4 and Tab. 5. Facesheet perforation is marked with " $\checkmark$ ", while for sign " $x$ " a no perforation situation appeared. Moreover, close up images of the central part of the impacted sandwich panels are presented in Fig. 5 and Fig. 6.

\begin{tabular}{|c|c|c|c|c|c|c|c|c|}
\hline \multirow{3}{*}{$\begin{array}{l}\text { Sandwich } \\
\text { panel }\end{array}$} & \multicolumn{4}{|c|}{ Damage area $\left[\mathrm{mm}^{2}\right]$} & \multicolumn{4}{|c|}{ Facesheet perforation } \\
\hline & \multicolumn{2}{|l|}{ Top } & \multicolumn{2}{|l|}{ Bottom } & \multicolumn{2}{|l|}{ Top } & \multicolumn{2}{|c|}{ Bottom } \\
\hline & PUR & PS & PUR & PS & PUR & PS & PUR & PS \\
\hline SPA_3 & 737.76 & 649.97 & 270.43 & 388.051 & $\checkmark$ & $\checkmark$ & $\mathrm{x}$ & $\mathrm{x}$ \\
\hline SPA_3.5 & 690.00 & 544.17 & 746.63 & 821.64 & $\checkmark$ & $\checkmark$ & $\mathrm{x}$ & $\checkmark$ \\
\hline SPA_4 & 746.73 & 576.23 & 872.05 & 872.55 & $\checkmark$ & $\checkmark$ & $\checkmark$ & $\checkmark$ \\
\hline SPB_3 & 726.05 & 733.07 & 165.06 & 243.40 & $\checkmark$ & $\checkmark$ & $\mathrm{x}$ & $\mathrm{x}$ \\
\hline SPB_3.5 & 641.78 & 658.91 & 653.25 & 776.02 & $\checkmark$ & $\checkmark$ & $\mathrm{x}$ & $\mathrm{x}$ \\
\hline SPB_4 & 662.14 & 614.95 & 822.31 & 895.89 & $\checkmark$ & $\checkmark$ & $\checkmark$ & $\checkmark$ \\
\hline SPC_3 & 741.74 & 654.18 & 58.93 & 185.14 & $\mathrm{x}$ & $\checkmark$ & $\mathrm{x}$ & $\mathrm{x}$ \\
\hline SPC_3.5 & 650.87 & 738.33 & 581.15 & 607.92 & $\checkmark$ & $\checkmark$ & $\mathrm{x}$ & $\mathrm{x}$ \\
\hline SPC_4 & 646.28 & 746.26 & 826.03 & 907.75 & $\checkmark$ & $\checkmark$ & $\checkmark$ & $\mathrm{x}$ \\
\hline
\end{tabular}

Table 4: Summary of damage events induced by impact loading in sandwich panels with composite facesheets.

\begin{tabular}{llccccc}
\hline & & \multicolumn{3}{l}{ Facesheet perforation } \\
$\begin{array}{l}\text { Sandwich } \\
\text { panel }\end{array}$ & Indentation depth [mm] & Top & \multicolumn{3}{l}{ Bottom } \\
& PUR & PS & PUR & PS & PUR & PS \\
SPAl_3 & 8.23 & 13.38 & x & x & x & x \\
SPAl_3.5 & 12.61 & 15.13 & $\checkmark$ & x & x & x \\
SPAl_4 & 15.84 & 16.87 & $\checkmark$ & $\mathrm{x}$ & $\mathrm{x}$ & $\mathrm{x}$ \\
\hline
\end{tabular}

Table 5: Summary of damage events induced by impact loading in sandwich panels with aluminum facesheets.

For the lowest impact velocity of $3 \mathrm{~m} / \mathrm{s}$, the upper facesheet of all sandwich panels with composite facesheets is perforated, irrespective of core type, except for the SPC_PUR panel, which is the most rigid one due to the PUR core and the composite facesheets with the highest amount of short glass fibers. The bottom facesheets present only matrix cracking, debonding and some fiber rupture, with no perforation (see Fig. 5). Composite sandwich panels with PUR foam core have a larger damage area on the upper facesheet and a smaller damage area on the bottom facesheet than those with PS foam core. The increased rigidity of the PUR foam reduces the absorption capability of the core and thus most of the impact energy is absorbed by the upper facesheet, which is more damaged. The sandwich panels with aluminum facesheets present a small indentation on the upper facesheet, with no perforation, and no visible damage on the bottom facesheet (see Fig. 5).

By increasing the impact velocity to $3.5 \mathrm{~m} / \mathrm{s}$ determines an important increase of the damage area in the bottom facesheets, almost 76\% for PUR panels and $64 \%$ for PS panels, while uppper facesheet perforation and debonding is almost the same for all composite sandwich panels. Moreover, the bottom facesheet of the less rigid composite sandwich panel, the SPA_PS panel, is perforated. The aluminum sandwich panels with PUR foam core, present local indentation and perforation of the 
upper facesheet, and a small bulge deformation on the bottom facesheet. Same as composite sandwiches, these panels with PS foam core show less damage on the upper facesheet, with no perforation, but a larger bulge deformation on the bottom facesheet. As a consequence, the indentation depth for sandwich panels with PS foam core is larger than those with PUR foam core (Tab. 5).

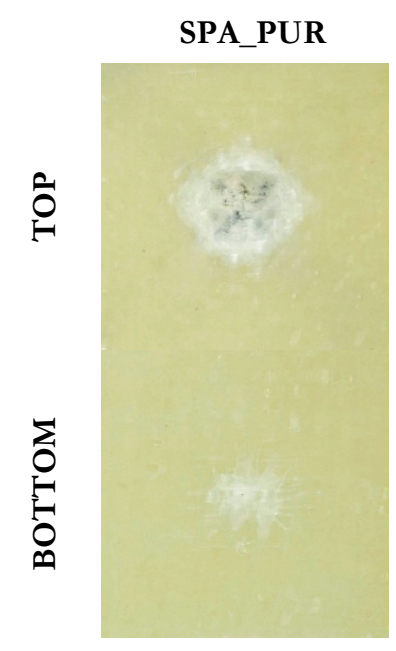

SPA PS

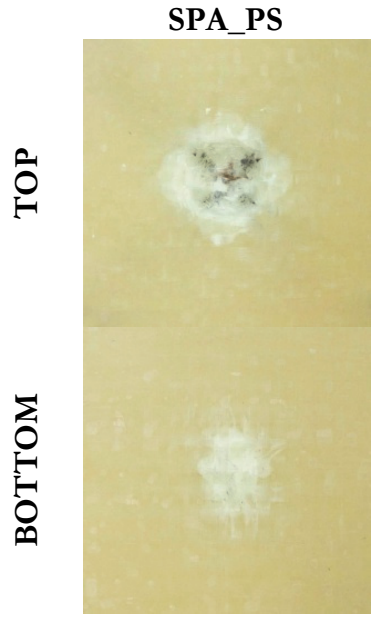

Figure 5: Failure of sandwich panels impacted
SPB_PUR

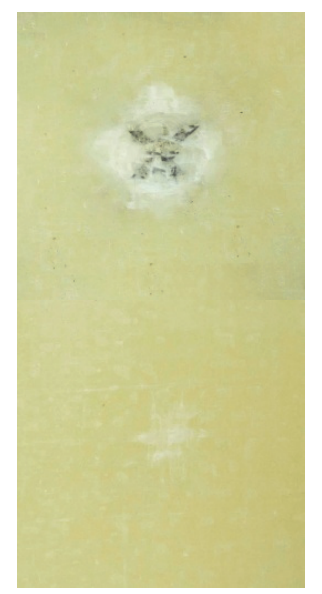

a)

SPB_PS

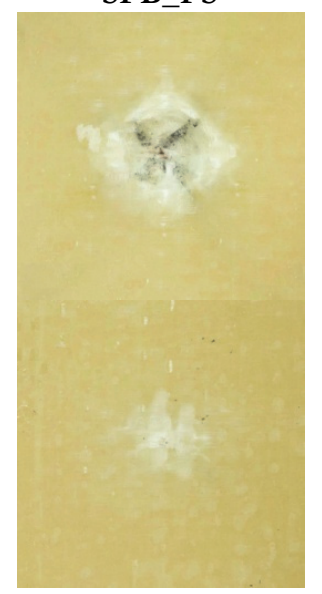

SPC_PUR

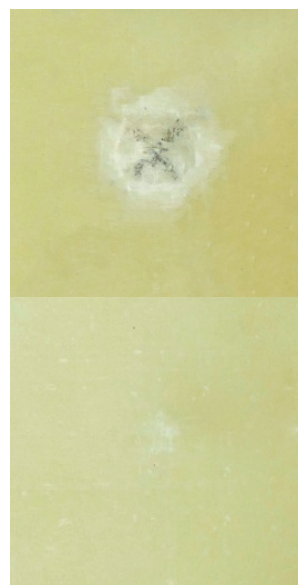

SPC PS

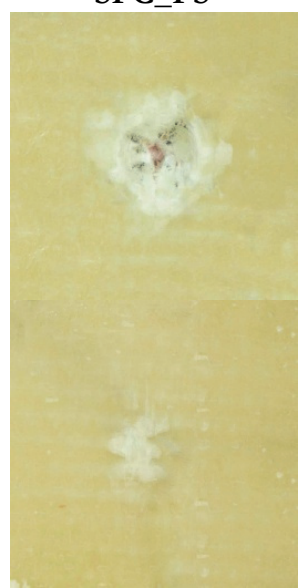

SPAl_PUR

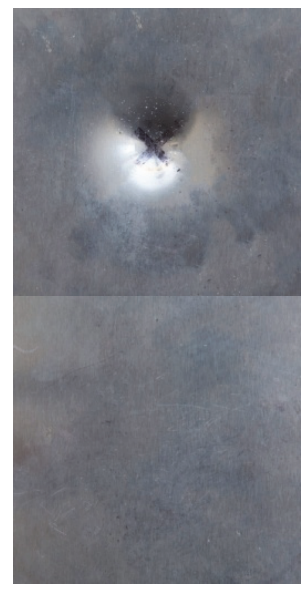

SPAl_PS

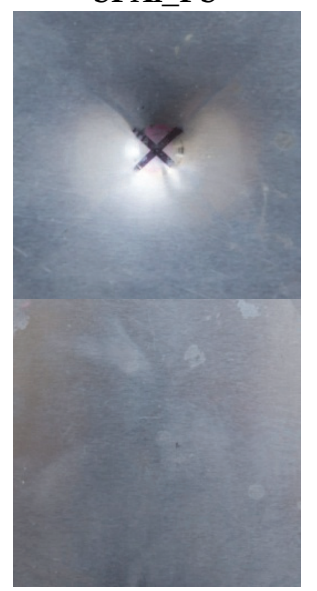




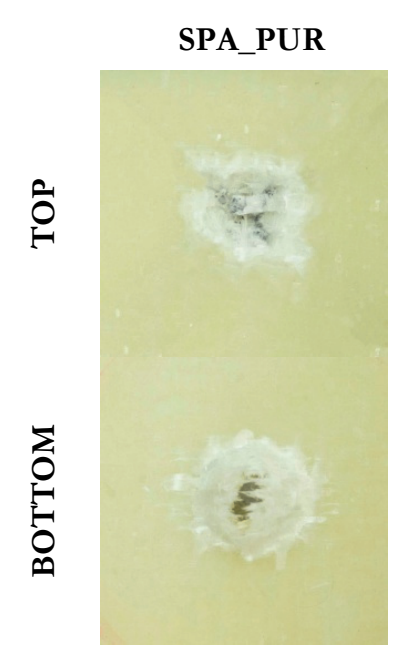

SPA PS

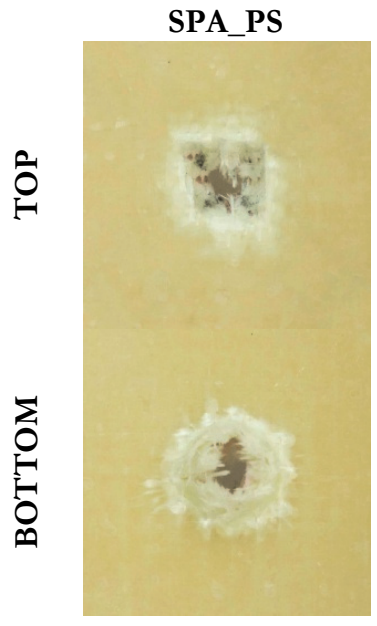

Figure 6: Failure of sandwich panels impacted at $4 \mathrm{~m} / \mathrm{s}$ : a) PUR foam core; b) PS foam core.

\section{CONCLUDING REMARKS}

7 his paper experimentally investigated the low velocity impact behavior of foam core sandwich panels with aluminum and glass fiber reinforced composite facesheets. The energy absorption capabilities and failure characteristics of these sandwich panels were analyzed in detail. Based on the results and discussions, the following conclusions can be drawn:

(1) The energy-time variation curves indicate a recovery of energy in the case of aluminum sandwich panels irrespective of impact velocity; for sandwich panels with composite facesheets this energy recovery is barely noticeable only at the lowest impact velocity.

(2) The energy absorbing capability of the sandwich panels is affected by the initial impact velocity on one hand, and facesheets and core type on the other hand. For the lowest impact velocity, PUR sandwich panels with aluminum facesheets absorb less energy than those with composite facesheets, while PS sandwich panels absorb almost the same amount of energy for both types of facesheets. For the highest impact velocity, the aluminum facesheets panels absorb the highest amount of energy regardless the core type.

(3) Three normalized parameters are used to quantify the effectiveness of impact energy absorption of the sandwich panels with PUR and PS core by using composite and aluminum facesheets. They are: normalized absorbed energy (NAE), specific energy absorption (SEA), and crush force efficiency (CFE). Higher they are, better it is from the point of view of engineering applications. That is, for the same core, the main question is: what is it better to use as facesheet with similar thickness: aluminum or GFRP? Or, for the same type of facesheet, PUR or PS foams are 
preferable? It looks like each normalized parameter gives specific information on the sandwich response and therefore the obtained information from all of them must be corroborated. At lower impact speeds composite facesheets do better than the aluminum ones; more rigid the facesheet and core (type C and PUR) are, the outcome is that the composite panel is surpassing the aluminum one in terms of SEA, but not so evidently for NAE and CFE. At the highest impact speed of $4 \mathrm{~m} / \mathrm{s}$ the parameter SEA is about the same for both types of facesheets, NAE increases using aluminum facesheets and CFE decreases.

(4) For composite facesheets panels the damaged area of the top facesheet is reduced if the facesheet is stiffer - type $\mathrm{C}$ versus type A, and by using the more rigid core - PUR versus PS. On the bottom facesheet, in the cases without perforation at 3 and $3.5 \mathrm{~m} / \mathrm{s}$, an important decrease of the damaged surface is produces by using PUR foam core instead of PS foam core (more than 3 times for type $C$ facesheet at $3 \mathrm{~m} / \mathrm{s}$ ). At $4 \mathrm{~m} / \mathrm{s}$ perforation of bottom facesheet is almost produced even for type $\mathrm{C}$ facesheet and the surface of the damaged area is greater for PS foam core than for PUR foam core, actually about the same regardless the type of the composite facesheet for each foam core type.

\section{ACKNOWLEDGEMENTS}

$\mathrm{M}$ iss Oana Alexandra Mocian acknowledges the $\mathrm{PhD}$ student scholarship given by the Ministry of National Education from Romania through the contract no. 06.40/2014 which made possible the present researches. All the authors acknowledge that this work was supported by a grant from the Romanian National Authority for Scientific Research and Innovation, CCCDI-UEFISCDI, project number 11/2015.

\section{REFERENCES}

[1] Gilioli, A., Sbarufatti, C., Manes, A., Giglio, M. (2014). Compression after impact test (CAI) on NOMEX ${ }^{\mathrm{TM}}$ honeycomb sandwich panels with thin aluminum skins, Compos. Part B-Eng., 67, pp. 313-325.

DOI: 10.1016/j.compositesb.2014.07.015.

[2] Zhang, Y., Zong, Z., Liu, Q., Ma, J., Wu, Y., Li, Q. (2017). Static and dynamic crushing response of CFRP sandwich panels filled with different reinforced materials, Mater. Design, 117, pp. 396-408, DOI: 10.1016/j.matdes.2017.01.010.

[3] Tan, C.Y., Akil, H.M. (2012). Impact response of fiber metal laminate sandwich composite structure with polypropylene honeycomb core, Compos. Part B-Eng., 43, pp. 1433-1438, DOI: 10.1016/j.compositesb.2011.08.036.

[4] Wang, H., Ramakrishnan, K.R., Shankar, K. (2016). Experimental study of the medium velocity impact response of sandwich panels with different cores, Mater. Design, 99, pp. 68-82, DOI: 10.1016/j.matdes.2016.03.048.

[5] Wei, K., Peng, Y., Qu, Z., He, R., Cheng, X. (2017). High temperature mechanical behaviors of lightweight ceramic corrugated core sandwich panels, Compos. Struct., 176, pp. 379-386, DOI: 10.1016/j.compstruct.2017.05.053.

[6] Jing, L., Xi, C., Wang, Z., Zhao, L. (2013). Energy absorption and failure mechanism of metallic cylindrical sandwich shells under impact loading, Mater. Design, 52, pp. 470-480, DOI: 10.1016/j.matdes.2013.05.090.

[7] Zhang, S., Dulieu-Barton, J.M., Thomsen, O.T. (2015). The effect of temperature on the failure modes of polymer foam cored sandwich structures, Compos. Struct., 121, pp. 104-113, DOI: 10.1016/j.compstruct.2014.10.032.

[8] McShane, G.J., Radford, D.D., Deshpande, V.S., Fleck, N.A. (2006). The response of clamped sandwich plates with lattice cores subjected to shock loading, Eur. J. Mech. A-Solids, 25, pp. 215-229, DOI: $10.1016 /$ j.euromechsol.2005.08.001.

[9] Jover, N., Shafiq, B., Vaidya, U. (2014). Ballistic impact analysis of balsa core sandwich composites, Compos. Part BEng., 67, pp. 160-169, DOI: 10.1016/j.compositesb.2014.07.002.

[10] Birman, V., Kardomateas, G.A. (2018). Review of current trends in research and applications of sandwich structures, Compos. Part B-Eng., 142, pp. 221-240, DOI: 10.1016/j.compositesb.2018.01.027.

[11] Chai, G.B., Zhu, S. (2011). A review of low-velocity impact on sandwich structures, P. I. Mech. Eng. L-J. Mat., 225(4), pp. 207-230, DOI: $10.1177 / 1464420711409985$.

[12] Pathipaka, R.K., Namala, K.K., Sunkara, N., Bandaru, C.R. (2018). Damage characterization of sandwich composites subjected to impact loading, J. Sandw. Struct. Mater., DOI: 10.1177/1099636218792717.

[13] Siivola, J.T., Minakuchi, S., Mizutani, T., Takeda, N. (2016). Evaluation of damage detectability in practical sandwich structure application conditions using distributed fiber optic sensor, Struct. Health Monit., 15, pp. 3-20, DOI: $10.1177 / 1475921715620002$.

[14] Akatay, A., Bora, M.O., Coban, O., Fidan, S., Tuna, V. (2015). The influence of low velocity repeated impacts on residual compressive properties of honeycomb sandwich structures, Compos. Struct., 125, pp. 425-433, 
DOI: $10.1016 /$ j.compstruct.2015.02.057.

[15] Feng, D., Aymerich, F. (2013). Damage prediction in composite sandwich panels subjected to low-velocity impact, Compos. Part A-Appl. Sci. Manuf., 52, pp. 12-22, DOI: 10.1016/j.compositesa.2013.04.010.

[16] Steeves, C., Fleck, N. (2004). Collapse mechanisms of sandwich beams with composite faces and a foam core, loaded in three-point bending. Part II: experimental investigation and numerical modeling, Int. J. Mech. Sci., 46(4), pp. 585608, DOI: $10.1016 /$ j.ijmecsci.2004.04.004.

[17] Jiang, B., Li, Z., Lu, F. (2015). Failure mechanism of sandwich beams subjected to three-point bending, Compos. Struct., 133, pp. 739-745, DOI: 10.1016/j.compstruct.2015.07.056.

[18] Vitale, J., Francucci, G., Xiong, J., Stocchi, A. (2017). Failure mode maps of natural and synthetic fiber reinforced composite sandwich panels, Compos. Part A-Appl. S., 94, pp. 217-225, DOI: 10.1016/j.compositesa.2016.12.021.

[19] Sokolinsky, V.S., Shen, H., Vaikhanski, L., Nutt, S.R. (2003). Experimental and analytical study of nonlinear bending response of sandwich beams, Compos. Struct., 60(2), pp. 219-229, DOI: 10.1016/S0263-8223(02)00293-3.

[20] Zhang, F., Liu, W., Fang, H., Jia, Z. (2019). Flexural behavior of composite sandwich beams with different kinds of GFRP ribs in flatwise and edgewise positions, Compos. Part B-Eng., 156, pp. 229-239.

DOI: $10.1016 /$ j.compositesb.2018.08.053

[21] Styles, M., Compston, P., Kalyanasundaram, S. (2007). The effect of core thickness on the flexural behavior of aluminum foam sandwich structures, Compos. Struct., 80(4), pp. 532-538, DOI: 10.1016/j.compstruct.2006.07.002.

[22] Massabò, R., Cavicchi, A. (2012). Interaction effects of multiple damage mechanisms in composite sandwich beams subject to time dependent loading, Int. J. Solids Struct., 49, pp. 720-738, DOI: 10.1016/j.ijsolstr.2011.11.012.

[23] He, W., Liu, J., Wang, S., Xie, D. (2018). Low-velocity impact response and post-impact flexural behaviour of composite sandwich structures with corrugated cores, Compos. Struct., 189, pp. 37-53, DOI: 10.1016/j.compstruct.2018.01.024.

[24] Funari, M.F., Greco, F., Lonetti, P. (2018). Sandwich panels under interfacial debonding mechanisms, Compos. Struct., 203, pp. 310-320, DOI: 10.1016/j.compstruct.2018.06.113.

[25] Funari, M.F., Greco, F., Lonetti, P., Spadea, S. (2019). A numerical model based on ALE formulation to predict crack propagation in sandwich structures, Frattura ed Integrità Strutturale, 47, pp. 277-293, DOI: 10.3221/IGF-ESIS.47.21.

[26] Park, J.H., Ha, S.K., Kang, K.W., Kim, C.W., Kim, H.S. (2008). Impact damage resistance of sandwich structure subjected to low velocity impact, J. Mater. Process. Tech., 201(1-3), pp. 425-430. DOI: $10.1016 /$ j.jmatprotec.2007.11.196.

[27] Crupi, V., Kara, E., Epasto, G., Guglielmino, E., Aykul, H. (2016). Theoretical and experimental analysis of glass fibre reinforced aluminium honeycomb sandwiches, J. Sandw. Struct. Mater., 20(1), pp. 42-69.

DOI: $10.1177 / 1099636216629375$.

[28] Zhu, S., Chai, G.B. (2013). Damage and failure mode maps of composite sandwich panel subjected to quasi-static indentation and low velocity impact, Compos. Struct., (101), pp. 204-214, DOI: 10.1016/j.compstruct.2013.02.010.

[29] Dawood, M., Ballew, W., Seiter, J. (2011). Enhancing the resistance of composite sandwich panels to localized forces for civil infrastructure and transportation applications, Compos. Struct., 93(11), pp. 2983-2991, DOI: 10.1016/j.compstruct.2011.05.004.

[30] Xie, Z., Zhao, W., Wang, X. (2017). Low-velocity impact behaviour of titanium honeycomb sandwich structures, J. Sandw. Struct. Mater., 20(8), pp. 1009-1027, DOI: $10.1177 / 1099636217728421$.

[31] Sun, G., Chen, D., Huo, X., Zheng, G., Li, Q. (2018). Experimental and numerical studies on indentation and perforation characteristics of honeycomb sandwich panels, Compos. Struct., 184, pp. 110-124, DOI: $10.1016 /$ j.compstruct.2017.09.025.

[32] ISO 6603-2:2000, Plastics -- Determination of puncture impact behaviour of rigid plastics -- Part 2: Instrumented impact testing, International Organization for Standardization, Geneva, Switzerland

[33] ASTM D7136/D7136M-15. Standard test method for measuring the damage resistance of a fiber-reinforced polymer matrix composite to a drop weight impact event, West Conshohocken, PA, USA: ASTM International, 2015.

[34] Mocian, O.A., Constantinescu, D.M., Sandu, M., Sorohan, St. (2018). Experimental and numerical analyses of the impact response of lightweight sandwich panels, Mater. Today-Proc., 5(13), pp. 26634-26641, DOI: $10.1016 /$ j.matpr.2018.08.128.

[35] Mocian, O.A., Constantinescu, D.M., Sandu, M., Sorohan, St. (2018). Experimental evaluation of the response of sandwich panels in low-velocity impact, P. I. Mech. Eng. L-J. Mat., DOI: 10.1177/ 1464420718798168.

[36] Lakshmana, C.R., Narayanamurthy, V., Simha, K.R.Y. (2016). Applied Impact Mechanics, John Wiley \& Sons Ltd, United Kingdom.

[37] https://imagej.nih.gov/ij/, last accessed January 19, 2019. 